\title{
Como possibilitar a integração do método Paulo Freire à Formação de Professores da EJA em Pensamento Computacional?
}

\author{
Soraya Roberta dos Santos Medeiros \\ Universidade Federal do Rio Grande do Norte (UFRN) \\ PPgITE - Natal - RN \\ soraya.roberta.js@gmail.com \\ http://orcid.org/0000-0002-6626-5963
}

Cibelle Amorim Martins

Universidade Federal do Rio Grande do Norte (UFRN)

PPgITE- Natal - RN

cibelle.martins@ufrn.br

http://orcid.org/0000-0001-9315-5113

\section{Resumo}

O Pensamento Computacional (PC) é um conjunto de técnicas da computação que podem ser aplicadas à resolução de diversos problemas. Contudo, a sua aplicação ainda está muito restrita à formação de discentes, sendo deixado de lado a docente. A preocupação aumenta ao observar que esses estudos já chegaram aos alunos da Educação de Jovens e Adultos (EJA), mas não em professores que atuam nesta modalidade. Nesse sentido, o presente trabalho tem como objetivo analisar a relação entre os pilares do PC e o método Paulo Freire na formação de professores da EJA e, para tanto, foi desenvolvido um curso com encontros síncronos e assíncronos com esses profissionais. Os resultados demonstraram que os docentes desconstruíram um mito que tinham sobre o PC e descobriram fontes para subsidiarem a construção de atividades específicas para a EJA.

Palavras-chave: Pensamento Computacional, Educação de Jovens e Adultos, metodologias ativas, formação de professores.

\section{How to enable an integration of the Paulo Freire method to EJA Teacher Training in Computational Thinking?}

\begin{abstract}
Computational Thinking (PC) is a set of computing techniques that can be applied to solve various problems. However, its application is still very restricted to the training of students, while the teacher training one is left aside. The concern increases when it is known that these studies have already reached the students of Youth and Adult Education (EJA), but not the teachers who work in this modality. In this sense, the present work aims to analyze the relationship between the PC pillars and the Paulo Freire method in the training of EJA teachers. A course was developed with synchronous and asynchronous meetings with these professionals for doing that. Results showed that the professors deconstructed a myth they had about PC and that they found sources to support the construction of specific activities for EJA.
\end{abstract}

Keywords: Computational Thinking, Youth and Adult Education, active methodologies, teacher training. 


\section{Introdução}

O Pensamento Computacional, conjunto de técnicas da computação que podem ser aplicadas à resolução de problemas diversos (Wing, 2006), está presente cada vez mais em tópicos de interesse de eventos ${ }^{1}$ e revistas ${ }^{2}$ sobre Educação em Computação ou Computação na Educação pelo mundo. A chegada dessa temática nos espaços de pesquisa tem suscitado o surgimento de técnicas, workshops, materiais e metodologias para a formação dos discentes. Contudo, ainda se percebe a escassez de propostas voltadas para serem utilizados nas formações dos professores. A questão torna-se mais problemática quando se volta a ótica para docentes que atuam em modalidades de ensino, tais como a Educação de Jovens e Adultos (EJA), pois ainda não existem trabalhos sendo aplicados com essa finalidade (Medeiros; Martins; Medeiros, 2021), (Medeiros, 2021). Afinal, a EJA possui um perfil distinto de professores e alunos (Arroyo, 2006).

Neste sentido, ensinar na EJA, qualquer que seja o conteúdo, não se resume a fazer uma breve pesquisa na internet e aplicá-la nas turmas da modalidade, ou ainda, tentar adaptar atividades do ensino regular e levá-las para jovens e adultos responderem. Assim, torna-se necessário conhecer as necessidades formativas desses discentes para possibilitar que exista uma relação entre as suas histórias de vida e o conteúdo de sala de aula. Do mesmo modo, deve ocorrer no ato da elaboração de atividades de Pensamento Computacional, uma vez que não é apenas ensinar a ligar blocos por meio de conectores lógicos e propor como se faz um jogo ou vídeo animado, mas ensinar o porquê e o como um jogo ou um vídeo podem ajudar a retratar a realidade desses discentes.

Frente ao exposto, chega-se a seguinte questão de pesquisa: Como a relação entre o Pensamento Computacional e o método de alfabetização de Paulo Freire pode contribuir na formação de professores que atuam na Educação de Jovens e Adultos? Em busca de responder a essa pergunta, propõe-se o objetivo: Analisar a relação entre os pilares do Pensamento Computacional e o método de Paulo Freire, com vistas a contribuir para o processo de formação de professores da Educação de Jovens e Adultos.

Para desenvolver os passos metodológicos do estudo, esta pesquisa enquadra-se na área de Ciências Humanas, tendo caráter interdisciplinar entre as áreas de Computação e Educação. Quanto aos seus objetivos, é classificada como uma pesquisa explicativa (Gil, 2010). No que concerne à sua natureza, segue uma abordagem qualitativa, uma vez que contempla a imersão do pesquisador no contexto em estudo através de diversas técnicas, a fim de obter subsídios que permitem uma melhor compreensão do objeto em estudo. Em relação aos procedimentos metodológicos, caracteriza-se como relato de experiência (Gil, 2008).

Nessa direção, apresenta-se, neste trabalho, um relato de experiência de um curso de formação de professores da EJA desenvolvido durante o contexto de ensino remoto emergencial. Além desses aspectos, cabe destacar que este trabalho é a sumarização de parte dos resultados da pesquisa de dissertação de mestrado de Soraya Medeiros, orientada pela professora Cibelle Martins. Para tanto, encontra-se registrado em Comitê de Ética em Pesquisa a $\mathrm{O}$ ensino de Pensamento Computacional na Formação de Professores da Educação de Jovens e Adultos por meio da Plataforma Brasil. ${ }^{3}$

No que concerne à organização do artigo, ele é descrito em seis seções, além desta introdução, a saber: a seção 2 e 3 apresentam as teorias que servem de base para fundamentar as análises deste trabalho; já a seção 4 dispõe de uma contextualização dos trabalhos relacionados. Na seção 5, tem-se a descrição metodológica do estudo,

\footnotetext{
${ }^{1}$ https://www.educompbrasil.org/simposio/2022/

${ }^{2}$ https://www.br-ie.org/pub/index.php/rbie/index

${ }^{3} \mathrm{https} / / /$ plataformabrasil.saude.gov.br/login.jsf
} 
possibilitando a sua replicação em outros contextos. A seção 6 se concentra em detalhar os principais resultados e, por fim, a seção 7, se debruça em apontar as conclusões do estudo.

\section{Método Paulo Freire de alfabetização}

A proposta do método Paulo Freire consiste em trabalhar com alguns padrões: criar um círculo de cultura, elencar as palavras geradoras e consequentemente desenvolver temas geradores problematizadores. O círculo de cultura ocorre nas interações entre discentes e docente em sala de aula, espaço em que os alunos compartilham e dialogam sobre sua vida e trabalho. Nisso, é possível extrair palavras em comum que servirão de base para se criar um diálogo crítico para trabalhar qualquer conteúdo em sala de aula (Freire, 1983). Além disso, o método Paulo Freire vai de encontro à proposta de infantilização da proposta pedagógica na EJA.

Para discutir sobre isso, tem-se o estudo de Márjori Réus (2013), a qual levanta algumas possibilidades que levam a esse cenário, tais como: a inadequação das atividades que são propostas para a EJA, com o enfoque e o entendimento de que a alfabetização se resume à aquisição de leitura e escrita, bem como a falta de aprofundamento nas temáticas, que se envolve em um pressuposto de falta de capacidade dos estudantes, assim também a dificuldade de formação docente específica para a EJA.

\section{Pensamento Computacional e Metodologias Ativas}

Pensamento Computacional não é saber mexer em um editor de texto ou jogar na internet, mas sim um conjunto de técnicas que possuem como base a computação e que fazem parte do cotidiano de todos os seres humanos por meio de processos como a abstração, a decomposição, o reconhecimento de padrões e os algoritmos (Blinkstein, 2008). O PC tem sido apontado como um meio para melhorar a interpretação de textos e o processo de leitura e escrita, independente do seu tipo de aplicação, se é plugada ou desplugada (Nunes; Santos, 2019).

Para desenvolver atividades do PC, tem-se observado estudos que inserem metodologias ativas nas formações (Medeiros et al., 2018). O conceito de Metodologias Ativas tem suas raízes na pedagogia de John Dewey, tendo como principal norte fornecer meios para que os alunos desenvolvessem autonomia e os professores a mediação. Existem diversos tipos de metodologias ativas, cada uma com suas características, tendo papéis para serem executados, tanto os docentes quanto os discentes, bem como o tipo de proposta avaliativa. Contudo, ainda é mais confortável, para alguns professores, trabalharem sem metodologias ativas, pois o método tradicional de ensino foi o que os atuais docentes mais praticaram em suas formações iniciais (Ferrarini; Saheb; Torres, 2019).

\section{Trabalhos relacionados}

Pasqual Júnior e Oliveira (2019) desenvolveram uma oficina por meio do Scratch para a formação de professores através de um estudo de caso. Como metodologia, eles utilizaram a observação do participante e a aplicação de dois questionários. A análise dos dados se deu com a escolha da análise de discurso para as questões abertas e com análise estatística descritiva para as questões quantitativas. Como resultados, relataram que os professores desconhecem a temática e, consequentemente, apresentam dificuldades em reconhecer a importância do uso do PC na sala de aula. 
Dall Agnol, Gusberti e Bertagnolli (2020) relataram o processo de elaboração, aplicação e avaliação de um jogo de tabuleiro denominado "Planetar" com professores que atuam na Educação Básica. Como metodologia, utilizaram a pesquisa bibliográfica, a revisão sistemática sobre $\mathrm{PC}$ e um estudo de caso. O principal resultado identificado na pesquisa foi o aumento do interesse por parte dos participantes em ensinar PC na educação básica.

No trabalho de Barros, Meira e Teixeira (2018), é descrito a implementação de um programa de formação de professores oferecida à rede municipal de ensino de um município do estado do Rio Grande do Sul. Para esse processo, os pesquisadores utilizaram como ferramenta de implementação o Scratch. As impressões dos professores com relação à formação foram desenvolvidas através das análises de conteúdo com processo de codificação. Como resultados, os autores apontam determinada resistência por parte dos professores em integrar atividades relacionadas ao pensamento computacional em seus encargos e práticas de ensino correntes.

Os estudos apresentados nesta seção corroboram a necessidade apresentada ao longo deste estudo sobre trabalhar Pensamento Computacional na formação de professores. De maneira geral, observa-se que os trabalhos estão se debruçando em aplicar ferramentas como Scratch e jogos de tabuleiro, sendo as mesmas propostas metodológicas encontradas em trabalhos na Educação Básica com discentes. Outro ponto identificado é a utilização de estudo de caso e aplicação de questionários. Contudo, observa-se a lacuna: não retratam a utilização dessas formações para professores que atuam na Educação de Jovens e Adultos e tampouco permitem que esses docentes abordem características do método Paulo Freire, que pode, inclusive, ser utilizado em qualquer nível de ensino, não se restringindo à EJA.

\section{Metodologia}

\section{1 .O Curso PensaEJA}

O curso se desenvolveu metodologicamente em duas etapas: I) diálogos e explanação dos conteúdos com os participantes e II) elaboração da sequência didática. A etapa I) foi destinada a discutir sobre a teoria que fundamenta os tópicos abordados e a dialogar com os docentes sobre suas atuações na EJA. Na etapa II), os docentes desenvolveram as sequências didáticas. O curso foi executado em cinco encontros, sendo três síncronos e outros dois assíncronos, na primeira semana do mês de outubro de 2021. As aulas formativas, assim denominados os encontros síncronos, ocorriam sempre à noite com duração de três horas. A proposta foi ministrada para cinco professores de uma escola no interior do Rio Grande do Norte que atuam na EJA nos componentes curriculares História, Geografia, Ciências, Matemática e Português. Para subsidiar o seu desenvolvimento foram utilizadas as ferramentas Google, sendo as aulas síncronas via Google Meet ${ }^{4} \mathrm{e}$ os materiais de suporte disponibilizados no Google Classroom. ${ }^{5}$

Para cumprir com a etapa I) e em busca de se encontrar possíveis relações entre o método Paulo Freire de alfabetização e os pilares do Pensamento Computacional, durante os encontros síncronos, foi possível realizar diálogos com o objetivo de compreender a relação dos professores com a EJA, em específico com os seus alunos e o uso de tecnologia digital nessa modalidade.

\footnotetext{
${ }^{4}$ https://meet.google.com/

${ }^{5} \mathrm{https} / / /$ classroom.google.com/

V. $19 \mathrm{~N}^{\circ}$ 2, Dezembro, 2021

DOI: https://doi.org/10.22456/1679-1916.121362
} 
Assim, os diálogos se davam da seguinte maneira: ao passo em que se explanava sobre o método de alfabetização de Paulo Freire, eram feitos questionamentos sobre como estavam sendo feitas e propostas as atividades nas turmas que eles ensinavam. Por exemplo: "O método Paulo Freire descreve a importância sobre ensinar adultos por meio de suas histórias de vida. Como vocês estão atuando nas turmas?". Além disso, à medida que o conceito sobre PC ia sendo descrito, eram postas questões sobre como eles estavam trabalhando aspectos como os pilares do $\mathrm{PC}$ ou as suas habilidades consequentes nas aulas. O objetivo dessas intervenções se concentrava em fazer com que o corpo docente refletisse sobre suas ações e as relações com as formações que estavam propiciando aos seus discentes com base nas falas que eles emitiam. Desses diálogos foram extraídos padrões que buscam exemplificar as relações do método Paulo Freire com o PC, por meio da observação que foi realizada nessas discussões. Tais respostas são detalhadas na seção de resultados.

Para atender à etapa II) foi proposto, ao longo da semana, que o corpo docente desenvolvesse uma sequência didática para aplicar o conhecimento que estava sendo compartilhado durante a formação em uma atividade prática. Contudo, um dos requisitos dessa proposta era que o material fosse elaborado para ser aplicado por outros professores que atuam na EJA. Assim, seria necessário trabalhar com uma linguagem com a sequência injuntiva. Desse modo, durante os encontros assíncronos, eles colocavam em prática as discussões e fundamentações teóricas. Tal atividade tinha como objetivo fazer com que os docentes olhassem para as suas produções em sala de aula e entendessem como poderiam ressignificar as práticas por meio da inserção de passos metodológicos do Pensamento Computacional na EJA.

No que concerne ao conteúdo programático trabalhado, foram elencados os seguintes assuntos: Pensamento Computacional por meio da sua definição, contextualização histórica, principais diferenças entre Computação desplugada e plugada, bem como o Pensamento Computacional na EJA e as relações críticas com a Base Nacional Comum Curricular (BNCC). Além do PC, discutiu-se sobre metodologias ativas, o método Paulo Freire na alfabetização de Jovens e Adultos e as suas intersecções com o Pensamento Computacional. Por sua vez, no Google Classroom foram inseridos materiais com vistas a fundamentar as propostas das sequências didáticas e servir de base para discussão nos momentos síncronos, bem como servir de base para comunicação e envio da sequência didática.

Para se ter uma contextualização de quais materiais foram utilizados, têm-se os seguintes links para os materiais: Almanaques da Computação ${ }^{6}$, Pensamento Computacional e Cultura Digital: discussões sobre uma prática para o letramento digital ${ }^{7}$. , Guia Programaê ${ }^{8}$ Que EJA Cabe na BCC? ${ }^{9}$, Paulo Freire na EJA ${ }^{10}$ Metodologias ativas e tecnologias digitais: aproximações e distinções ${ }^{11}$ e Movimento metodologias ativas na EJA. ${ }^{12}$ Esses materiais foram escolhidos com base nas citações dos trabalhos relacionados utilizados para fundamentar as lacunas na área de pesquisa em questão.

\footnotetext{
${ }^{6} \mathrm{http}: / /$ almanaquesdacomputacao.com.br/gutanunes/publications/S12V2.pdf

${ }^{7}$ https://www.br-ie.org/pub/index.php/sbie/article/view/8856/6410

${ }^{8} \mathrm{https}$ ://fundacaotelefonicavivo.org.br/wp-content/uploads/pdfs/Guia_Final_06_09_2018.pdf

${ }^{9} \mathrm{https}: / / \mathrm{www}$.youtube.com/watch? $\mathrm{v}=\mathrm{VZyJ}$ Jiq-C3TE\& $\mathrm{t}=42 \mathrm{~s}$

${ }^{10} \mathrm{https}: / / \mathrm{www}$. youtube.com/watch? $\mathrm{v}=\mathrm{SzL} \_\mathrm{VJjSESw} \& \mathrm{t}=3 \mathrm{~s}$

${ }^{11} \mathrm{https}$ ://periodicos.ufrn.br/educacaoemquestao/article/view/15762

$12 \mathrm{https} / / / \mathrm{www}$.youtube.com/watch?v=brQI1MEBo
} 


\section{Resultados e discussões}

Nesta seção serão sumarizadas as principais questões apresentadas ao longo do curso, fruto dos diálogos com os professores e das observações realizadas. A partir disso, foram extraídos os tópicos que relacionam o Pensamento Computacional ao Método de alfabetização de Paulo Freire e que buscam responder à questão de pesquisa delineada na Introdução.

\subsection{A desconstrução do mito do Pensamento Computacional}

No início da formação os docentes não entendiam sobre Pensamento Computacional e o viam como algo distante das suas realidades, pois mal utilizavam recursos computacionais e associavam o termo a ter que aprender a programar para ensinar os discentes da EJA a como conseguirem um trabalho na área. Com isso, eles construíram um mito sobre a proposta. Para desconstruir esse mito os docentes foram postos a refletir sobre suas atitudes por meio das últimas atividades que tinham feito para as suas turmas. Com isso, eles iam comentando que já utilizavam boa parte de suas ações em relação ao Pensamento Computacional, contudo, de maneira distorcida ou sem nexo com o método Paulo Freire. Um exemplo de que estavam desenvolvendo as habilidades do Pensamento Computacional foram as sequências didáticas que eles apresentaram na finalização do curso, ficando demonstrado pelas questões que levavam à infantilização das atividades e colocaram ações que se correlacionavam com a vida dos alunos que já são jovens e adultos, assim como como a deles, os professores. Com essas reflexões, eles começaram a levantar hipóteses sobre as possíveis causas dos alunos se desinteressarem pelos conteúdos e a dificuldade de conseguir um maior engajamento com a aplicação das atividades. Uma das hipóteses levantadas foi: "os discentes sentem dificuldades ao executarem determinados problemas que passamos porque eles estão mal formulados metodologicamente, logo, desistem de fazer".

\subsection{A descoberta de fontes e metodologias para trabalhar na EJA}

Outro resultado extraído do curso foi a descoberta por parte dos professores das diversas fontes sobre a EJA, pois os docentes nunca tinham participado de um curso de formação específico para a essa modalidade. Diante desse cenário, eles relataram a dificuldade de encontrar materiais específicos e argumentaram que utilizavam materiais que faziam para suas turmas do ensino regular, pois não sabiam como produzir ou onde consultar fontes ou exemplos para fundamentar a produção para a EJA. Além desse contexto, eles relataram a dificuldade de inserir metodologias ativas nas atividades, já que boa parte dos seus discentes esperavam atividades feitas em sala de aula ou de fáceis resolução, visto que possuíam pouco tempo para exercitarem em casa. Assim, citaram como satisfatórias e bem acessíveis a descoberta de metodologias ativas, como a Peer Instruction e Aprendizagem Baseada em Problemas. Todos esses resultados reforçam o argumento levantado por Marjorie Reús (2013) sobre a falta de formação dos professores para atuar na EJA e as suas consequentes problemáticas fruto desses desdobramentos. 


\subsection{Sequência didática}

Nesta seção serão apresentadas duas sequências produzidas por dois dos docentes a fim de ilustrar de forma sumária os resultados das atividades, já que se tem a limitação de espaço em cada proposta submetida neste periódico.

\section{Quadro 1. Sequência didática - Cartografia através do Google Maps}

Eixo de Ensino: O planeta e/ou Cuidar da vida, sua e do outro

Objetivo(s): (a) Estudar cartografia a partir de ferramentas digitais; (b) Utilizar ferramentas pouco exploradas em equipamentos; (c) Aperfeiçoar a navegação no espaço geográfico.

Conteúdo(s): (a) Cartografia Básica; (b) Ferramentas digitais de mapa; (c) Navegação com endereços, rotas e mapas digitais.

Público-alvo: $4^{\circ}$ e $5^{\circ}$ períodos do EJA

Tempo estimado: 2 aulas

Material necessário: Ter um computador ou smartfone com acesso à internet, saber o endereço em que se reside e o endereço da escola. Além disso, material escolar básico como caderno e lápis e caneta.

Desenvolvimento

$1^{\text {a }}$ etapa - Introdução: No final da década de 1990, o uso dos computadores e o acesso à internet já eram realidades tão corriqueiras que pouca gente se lembra de como era possível fazer alguma coisa sem o auxílio dessas ferramentas. Naquela época, o filósofo francês Pierre Lévy, um respeitado estudioso da chamada cibercultura, destacou o extraordinário potencial de comunicação e informação da rede mundial de computadores. Atualmente com a utilização dos programas lançados pelo Google (maps.google.com) e outros programas que nos ajudam a localizar endereços residenciais, bairros, pontos de comércio, entre outros. Através de poucos cliques podemos visualizar ruas e casas em grandes metrópoles, enxergar detalhes exuberantes do relevo, vegetação e hidrografia dos continentes e se desfrutar de vários cenários. $2^{\mathbf{a}}$ etapa: Conversa com a turma sobre quem conhece o google Maps e explicar as possibilidades de uso da ferramenta. Como podemos aplicar essa ferramenta no nosso dia a dia, o que podemos aprender e onde podemos aplicar esses conhecimentos. De um ponto a outro dos trajetos, a tela do computador ou celular mostra o percurso feito e apresenta visões aéreas em diferentes ângulos, como se o internauta estivesse vendo o mundo a partir da janela de um avião. Deixar um momento a turma explorando a ferramenta e ajudar aqueles que não tem tanta familiaridade com o google Maps.

$3^{\text {a }}$ etapa: Neste momento o professor vai pedir para cada aluno escolher um endereço, podendo ser da sua casa e traçar a rota, do seu endereço até o endereço da escola, a partir deste momento o aluno vai ter a sua disposição informações de rotas que poderá fazer até o seu destino, tempo estimado, se este percurso será feito a pé ou de carro, vista aérea disponivel atraves de imagem de satélites\&quot; street view\&quot; lugares de referência entre um ponto e outro, pontos cardeais, etc. Será neste momento, onde podemos aplicar algumas questões para serem solucionadas pelos alunos a partir dos dados constatados. Busque coloca questões com situações do cotidiano do aluno para promover um pensamento crítico das suas ações durante o dia a dia, como meios de transporte utilizados, promoção de saúde física, custos com deslocamento, reconhecimento de possíveis pontos históricos da localidade e mapeamento urbano e navegação no seu lugar.

Pontos de contextualização: (a) Busca uma rota alternativa da sua rotina; (b) Registrar a diferença de tempo entre fazer a rota a pé e fazer por meio de transporte; (c) Registrar pontos de referência na rota; (d) Registrar pontos históricos na rota; (e) Buscar uma comparação dos benefícios de mudar o meio de transporte utilizado na rota; (f) Analisar os custos com o deslocamento na rota; (g) Direções cardeais e/ou colaterais tomadas na rota de acordo com os pontos de referência.

Avaliação: A avaliação será de forma contínua, durante todas as fases do plano, através da participação, do empenho e da capacidade de utilização da tecnologia para fazer a tarefa. Além disso podemos traçar algumas questões baseadas nos pontos de contextualização para servirem como avaliação qualitativa e/ou quantitativa para a ampliação do processo avaliativo.

Fonte: Elaborado pela autora por meio da produção dos docentes do curso

Quadro 2. Sequência didática - (In)segurança alimentar no Brasil: Vulnerabilidades sociais e necessidade metabólicas

Componente Curricular: Ciências

Eixo temático: Desigualdades Sociais

Duração: 6 Aulas 
Espaço: Sala de Aula

Nível Escolar: Modalidade EJA $\left(5^{\circ} \mathrm{P}\right)$

Caracterização do Potencial Didático da Temática: Presente no cotidiano; Temática Interdisciplinar (Utilizar conhecimentos matemáticos, químicos e biológicos) Discussão de valores morais; Levar os indivíduos a tomada de decisões.

Objetivos: i) Compreender se a (in)segurança alimentar é decorrente de ações atuais ou históricas; Identificar níveis de insegurança alimentar desde uma visão nacional quanto local; ii) Discutir sobre o alimento enquanto eixo transformador de um indivíduo na sociedade; Refletir sobre estratégias para pensar em uma alimentação saudável no cotidiano.

Descrição das Atividades da sequência de ensino

Aulas 01- Explanação do tema com uso de texto científico (Plataformas de Ciências), a fim de sondar conhecimentos existentes sobre a temática.

Aula 02-Elaborar alguns QRCode e distribuir pela sala, no intuito dos alunos utilizarem seus celulares para investigar as informações sobre as diversas inseguranças alimentares vivenciadas pela população. Vale ressaltar que, ao longo desse processo, é necessário lançar questionamentos para indagar os alunos diante de cada notícia assimilada por eles.

Aula 03- Utilizar mídias (Documentário ou animação) sobre como os alimentos, promovem o bem-estar do corpo, e resgatar os conhecimentos iniciais sobre a insegurança alimentar.

Aula 4-Reunir encartes alimentares de estabelecimentos, a fim de dialogar sobre o preço dos alimentos e como isso intensifica a insegurança alimentar dos brasileiros. Projetar esse material via Datashow para que todos possam acompanhar.

Aula 5- Utilizar o aplicativo MentiMeter para iniciar uma discussão sobre marcas que os estudantes consideram "melhores", A intenção aqui é deles apontar 3 marcas, o professor não irá revelar a questão sanitária por trás delas.

Aula 6- Nessa última aula, os alunos junto do professor podem traçar estratégias para introduzir uma alimentação saudável. A ideia é dividir a sala em grupos e distribuir fichas (elaboradas pelo canva) para que um dos alunos seja "monitorado" ou colocado como "Cobaia", durante esse experimento voltado a sua rotina alimentar. As refeições, horas e quantidades deverão ser anotadas pelos colegas, na intenção de analisar os aspectos positivos e negativos dos alimentos ingeridos por ele.

Recursos Didáticos: Uso de smartphones; Datashow; Uso de Mentimeter e QRCode; Papel A4/ Fichas de Observação Alimentar e Canva.

Metodologia Ativa : Abordagem baseada em problemas.

Proposta Avaliativa: Avaliação será de forma contínua mediante a participação dos estudantes nas atividades propostas, entretanto, a atividade final de observação alimentar, terá um peso maior na somatória, visto que permite que os alunos demonstrem autonomia, organização didática e engajamento na atividade.

Passo a Passo: i) Consulte seus alunos para averiguar a possibilidade em utilizar os aplicativos mencionados na sequência; ii) Dedique um tempo para conhecer softwares que serão inseridos nas aulas, isso é muito importante para que tenha segurança em utilizá-los; iii) Escolher as mídias visuais que serão trabalhadas na temática, existe diversas, fique à vontade para escolher aquela que atende melhor seu público. Iv) As fichas de observação alimentar podem ser desenvolvidas por outros softwares, mas o canva oferece diversos designers lúdicos e divertidos.

Fonte: Elaborado pela autora por meio da produção dos docentes do curso

\subsection{O que dizem as sequências didáticas}

A proposta desenvolvida pelo docente da sequência Cartografia através do Google Maps, no Quadro 1, foi elaborada como uma atividade desplugada. De maneira geral, atendeu ao propósito de atuar com uma sequência injuntiva e permitir que outros professores consigam replicar o material. Um dos pontos apresentados da junção do PC com o Método Paulo Freire é a definição temática que busca relacionar o desenvolvimento da atividade com o contexto de vida do discente por meio da concretização de uma atividade de rota no Google Maps. Com isso, é possível trabalhar, por exemplo, o conceito círculo de cultura por meio das palavras geradoras que visam iniciar uma discussão sobre o ambiente em que se vive. Contudo, essa escolha não ficou tão clara nos objetivos, e sim na seção de contextualização. 
Nela, é possível entender melhor que um possível desdobramento da atividade seria a escolha por uma rota mais curta para fazer, por exemplo, a entrega de um alimento via delivery. Com isso, levar o aluno a refletir sobre como esse detalhe pode influenciar no gasto com gasolina no final do dia. Em relação ao Pensamento Computacional, são evidenciadas as etapas de abstração, onde o discente faz uso para saber selecionar qual de fato é a melhor rota; a decomposição, pois precisará ir de A a B e assim terá que entender quais são as etapas a se fazer, bem como o reconhecimento de padrões, onde ele saberá com base em experiências passadas que seguindo determinado trecho pode gastar mais ou menos combustível/tempo de deslocamento. Além disso, o algoritmo, pois precisará esquematizar todas os passos para se fazer o deslocamento de A a B.

Acerca da sequência didática do Quadro 2, (In)segurança alimentar no Brasil: vulnerabilidades sociais e necessidade metabólicas, de maneira geral, é possível observar que atingiu a expectativa de produção desplugada, com o enfoque em metodologias ativas (Medeiros et al., 2018) e na execução de uma atividade que vise desenvolver a produção escrita ou a aquisição da leitura por meio da área de ciências naturais. Além disso, relacionou o PC com o método Paulo Freire por meio da execução de habilidades do PC (Nunes; Santos; 2019). Assim também, levantou a discussão sobre como um conteúdo programático pode se relacionar com o cotidiano dos alunos que estudam na EJA.

\section{Conclusões}

A proposta de inserir diálogo reflexivo enquanto se realizava a formação com professores se mostrou salutar por ser uma maneira distinta de compartilhar o conteúdo. Nesse sentido, não se tratava de transmitir o conteúdo, mas criar um ambiente que tivesse como base metalinguística o método Paulo Freire de alfabetização, sobre o qual é possível questionar práticas, preconceitos em forma de ações e formações com base no que se está posto como certo.

Um dos motivos que pode levar a inserção de materiais do ensino regular na modalidade EJA pode ser a falta de formação e conhecimento dos professores para atuar na modalidade. Isso porque um dos argumentos mais relatados pelos professores ao longo da formação foi essa ausência de conhecimento sobre onde e como trabalhar questões que fizessem sentido com a vida dos seus alunos. Como trabalhos futuros, pretende-se compilar as sequências didáticas que foram apresentadas neste estudo com as outras elaboradas pelos demais professores em um Guia. $\mathrm{O}$ objetivo dessa ação será difundir a formação e permitir que mais professores possam executar práticas motivadoras e eficazes em suas aulas.

\section{Referências}

ARROYO, M. Formar educadores de jovens e adultos. In: SOARES, L. (org.). Formação de educadores de jovens e adultos. Belo Horizonte: Autêntica/MEC/ UNESCO, 2006.

BARROS, T. T.; REATEGUI, E. B.; MEIRA, R. R.; TEIXEIRA. Avaliando a formação de professores no contexto do pensamento computacional. RENOTE, 16(2), 2018.

BLIKSTEIN, P. O pensamento computacional e a reinvenção do computador na educação. 2008. Disponível em: http://www.blikstein.com . Acesso em: 19 out. 2021.

BATHKE, J.; RAABE, A. Pensamento Computacional na Educação de Jovens e Adultos: lições aprendidas. Anais dos Workshops do Congresso Brasileiro de 
Informática na Educação, [S.1.], p. 1087, nov. 2016. Disponível em: https://www.brie.org/pub/index.php/wcbie/article/view/7034. Acesso em: 19 out. 2021.

DALL AGNOL, A.; GUSBERTI, C.; BERTAGNOLLI, S. C.; O ensino de pensamento computacional através de um jogo de tabuleiro em ambiente desplugado: relato de experiência de formação docente. RENOTE. 18(1), 2020.

FERRARINI, R., SAHEB, D., \& TORRES, P. L. Metodologias ativas e tecnologias digitais:. Revista Educação Em Questão, 57(52). 2019. https://doi.org/10.21680/19811802.2019v57n52ID15762

FREIRE, P. Educação como prática da liberdade. 14. ed. São Paulo: Paz de Terra, 1983.

MEDEIROS, S. R. S. M; et al. Ensino de algoritmos através de Poesia Compilada e Computação Desplugada: Relato de experiência com alunos de Ensino Fundamental. In: WORKSHOP DE INFORMÁTICA NA ESCOLA, 24. 2018, Fortaleza, CE. Anais [...]. Porto Alegre: Sociedade Brasileira de Computação, 2018. p. 381-390.

DOI: https://doi.org/10.5753/cbie.wie.2018.381.

MEDEIROS, S. R. S.; MARTINS, C. A.; MEDEIROS, I. G. Materiais didáticos utilizados nas formações de professores em Pensamento Computacional. In: SIMPÓSIO BRASILEIRO DE INFORMÁTICA NA EDUCAÇÃO, 32, 2021, Online. Anais [...]. Porto Alegre: Sociedade Brasileira de Computação, 2021 . p. 1096-1106.

DOI: https://doi.org/10.5753/sbie.2021.218681.

MEDEIROS, S. R. S. O Pensamento Computacional como um processo de tema gerador em um mundo imerso por algoritmos. Janaina Abreu, Paulo Roberto Padilha (Org). São Paulo: Instituto de Educação e Direitos Humanos Paulo Freire. 2021. p. 193 $-201$.

GIL, A. C. Como elaborar projetos de pesquisas. 5. ed. São Paulo: Atlas, 2010.

GIL, A. C. Como elaborar projetos de pesquisa. 4. ed. São Paulo: Atlas, 2008.

PASQUAL JÚNIOR, A. P.; OLIVEIRA, S. D. Pensamento computacional: uma proposta de oficina para a formação de professores. RENOTE, 17(1), 2019.

RÉUS, M. B. “Caprichem nas folhinhas": a infantilização das práticas pedagógicas e a docência da EJA. 2013. 50 f. Tese (Doutorado) - Curso de "Caprichem nas Folhinhas": A Infantilização das Práticas Pedagógicas e A Docência da Eja, Universidade Federal do Rio Grande do Sul, Porto Alegre, 2013. 